\title{
Distributed Optimal Voltage Control for VSC-HVDC Connected Large-Scale Wind Farm Cluster Based on Analytical Target Cascading Method
}

\author{
Huang, Shengli; Wu, Qiuwei; Zhao, Jin; Liao, Wu
}

Published in:

IEEE Transactions on Sustainable Energy

Link to article, DOI:

10.1109/TSTE.2019.2952122

Publication date:

2020

Document Version

Peer reviewed version

Link back to DTU Orbit

Citation (APA):

Huang, S., Wu, Q., Zhao, J., \& Liao, W. (2020). Distributed Optimal Voltage Control for VSC-HVDC Connected Large-Scale Wind Farm Cluster Based on Analytical Target Cascading Method. IEEE Transactions on

Sustainable Energy, 11(4), 2152 - 2161. https://doi.org/10.1109/TSTE.2019.2952122

\section{General rights}

Copyright and moral rights for the publications made accessible in the public portal are retained by the authors and/or other copyright owners and it is a condition of accessing publications that users recognise and abide by the legal requirements associated with these rights.

- Users may download and print one copy of any publication from the public portal for the purpose of private study or research.

- You may not further distribute the material or use it for any profit-making activity or commercial gain

- You may freely distribute the URL identifying the publication in the public portal 


\title{
Distributed Optimal Voltage Control for VSC-HVDC Connected Large-Scale Wind Farm Cluster Based on Analytical Target Cascading Method
}

\author{
Sheng Huang, Qiuwei Wu*, Jin Zhao, Wu Liao
}

\begin{abstract}
This paper proposes an analytical target cascading (ATC) based distributed optimal voltage control (DOVC) scheme for the voltage-source-converter high-voltage-directcurrent (VSC-HVDC) connected large-scale wind farm cluster (WFC). The aims are to minimize the voltage fluctuations of the point of connection (POC), collector buses, and wind turbine (WT) terminal buses inside the WFC while regulating the bus voltages close to the rated voltage and smooth the reactive power outputs of the WTs. With the DOVC scheme, the large-scale strongly coupled sensitivity-based voltage optimization problem is decomposed and solved in the WFC voltage-sourceconverter (WFCVSC) controller and sub-wind farm controllers in parallel. The DOVC scheme considers the $N-1$ principle to improve the reliability, and distributes computation burden to several controllers to achieve better scalability of the WFC. The optimization subproblems are solved with local constraints and local measurements while guaranteeing the optimality of the primal optimization problem. A WFC with 5 wind farms and each wind farm consisting of 20 WTs is used to validate the proposed DOVC scheme.
\end{abstract}

Index Terms-analytical target cascading (ATC), distributed, voltage control, wind farm cluster (WFC).

\section{INTRODUCTION}

D Ue to its excellent continuity and wind energy capture capability, offshore wind power has attracted increasing attention. With the rapid development of offshore wind farms (WFs), the cost effective collection and transmission of largescale offshore wind power plants are becoming increasingly relevant [1], [2]. From a cost-benefit point of view, voltagesource-converter high-voltage-direct-current (VSC-HVDC) is preferred as a suitable transmission technology for large-scale offshore wind power plants [3], [4].

With the increasing penetration of wind power in power systems, large-scale offshore wind farm clusters (WFCs) with many sub-wind farms (WFs) are being connected to grids

Corresponding author: Qiuwei Wu, (e-mail: qw@elektro.dtu.dk).

S. Huang and Q. Wu are with the Center for Electric Power and Energy (CEE), Department of Electrical Engineering, Technical University of Denmark (DTU), Kgs. Lyngby, 2800 Denmark (e-mail: huang98123@163.com, qw@elektro.dtu.dk ).

J. Zhao is with the Key Laboratory of Power System Intelligent Dispatch and Control of Ministry of Education, Shandong University, Jinan 250061, China (e-mail: jinzhao_sdu@mail.sdu.edu.cn)

W. Liao is with electrical engineering in the College of Electrical and information engineering, Hunan University, Changsha 410082, China. (e-mail: liaowu1988@hnu.edu.cn) through the VSC-HVDC transmission system, creating challenges for system operators. Modern WFCs are required not only to provide ancillary services to comply with grid code requirements [5], [6], but also to enhance the operation performance of the WFC to adapt to the stochastic and intermittent nature of wind energy. In general, the wind turbines (WTs) inside the WFC are connected through long medium voltage (MV) feeders. The active power change has a significant impact on the voltage variation due to the low $\mathrm{X} / \mathrm{R}$ ratio of the MV feeder [7]. The WTs located at the end of feeders have a risk of being tripped because their terminal voltages may exceed their threshold [8].

Therefore, the voltage control of a large-scale WF/WFC is an important task to guarantee secure operation while considering the economical operation of the WF/WFC [9], which has motivated a number of studies. In [10], a variable droop gain control scheme was proposed to mitigate voltage fluctuations at the point of connection (POC), which fully utilizes the voltage regulation capability of each WT converter. An MPC based centralized optimal voltage control scheme was proposed in [11], [12] for VSC-HVDC connected offshore WFs. The aims are to keep the voltage within a feasible range while taking the economical operation of the WFs into consideration. Ref. [13] proposed an approach for pilot-bus selection that considers both the response of the generators and the wind power fluctuation to maintain the system at the desired voltage profile. In [14], [15], centralized optimal reactive power dispatch strategies were proposed to minimize the total electrical losses of the WF, including not only the losses in cables and WT transformers but also the losses inside the wind energy generation systems. For distributed/hierarchical voltage control, a distributed control scheme based on the consensus protocol method was proposed in [16]. The aim is to improve the voltage profile and eliminate the centralized communication. In [17], an ADMM based hierarchical voltage control scheme was proposed. The central unit only needs to solve an optimization problem without constraints, while the constraints are solved with a simple augmented Lagrangian function in local units in a parallel manner. A two-tier voltage control scheme was proposed in [18] for a large-scale WFC. The collector bus voltage of each sub-WF is controlled by the upper-level control scheme in a distributed manner, while the voltages of the WT terminal buses are regulated by the 
lower-level control scheme in a hierarchical manner.

According to the above analysis, voltage control of WFs/WFCs can be classified into decentralized control, centralized control, and distributed/hierarchical control. Decentralized control mainly regulates voltages by using a droop controller or a proportional integral (PI) controller. Although the decentralized control can eliminate the requirement of the central unit, the optimal solution cannot be obtained. With the WFC growing both in number and size, considering the stochastic and intermittent nature of wind energy, centralized control might fail to obtain the optimal solution due to the high computation burden of the central unit. For the existing distributed/hierarchical control schemes, hierarchical control still requires a central unit to coordinate all the WTs inside the WFC. Distributed control mainly uses a two-tier control framework. From the WFC point of view, the solution is suboptimal.

To address the above issues, an analytical target cascading (ATC) method-based distributed optimal voltage control (DOVC) scheme is proposed for the VSC-HVDC connected large-scale WFC. The ATC method is an augmented Lagrangian relaxation based decomposition method [19], [20], which provides certain flexibilities in the coordination of problems and the selection of penalty functions [21], [22]. The aims of the proposed method are to minimize the voltage fluctuations of the POC, collector buses, and WT terminal buses while regulating the bus voltages close to the rated voltage, and smooth the reactive power outputs of the WTs inside the WFC. With the ATC method, the large-scale optimization problem is decomposed to several optimization subproblems and solved in the WFCVSC and sub-WF controllers in a distributed manner. Each sub-WF controllers only needs to coordinate the reactive power outputs of their corresponding WTs inside the subWF with local constraints and local measurements. The main contributions are summarized as follows:

1. A DOVC scheme is designed for the large-scale VSCHVDC connected WFC. The large-scale strongly coupled sensitivity-based voltage optimization problem is decomposed. With the DOVC scheme, the requirement of a central controller is eliminated.

2. The WFCVSC and sub-WF controllers are operated in a distributed manner which considers $N-1$ principle to improve the reliability of the WFC. Compared to the conventional centralized optimal control, the optimization task is distributed to several controllers to reduce the computation burden of the WFC central controller.

3. The exchanged information only includes the shared control variables with their neighboring controllers, implying better protection of the information privacy.

The rest of the paper is organized as follows. Section II provides an overview of the DOVC scheme. Centralized optimal voltage control of the WFC is presented in Section III. The ATC-based distributed solution method for the VSCHVDC connected WFC is described in Section IV. Finally, simulation results are presented and discussed in Section V, followed by the conclusions.

\section{Control Architecture}

\section{A. Configuration of WFC}

Fig. 1 shows the configuration of a VSC-HVDC connected large-scale offshore WFC. The WFC consists of several subWFs. Each sub-WF is connected to a $33 \mathrm{kV} / 155 \mathrm{kV}$ transformer. The high voltage (HV) side of each transformer is connected to the POC through a $20 \mathrm{~km} \mathrm{HV}$ transmission cable. The power generated by the WFC is transmitted to the onshore AC grids through a VSC-HVDC system. Each subWF consists of two feeders. Several WTs are connected by a feeder and displaced with a distance of $4 \mathrm{~km}$.

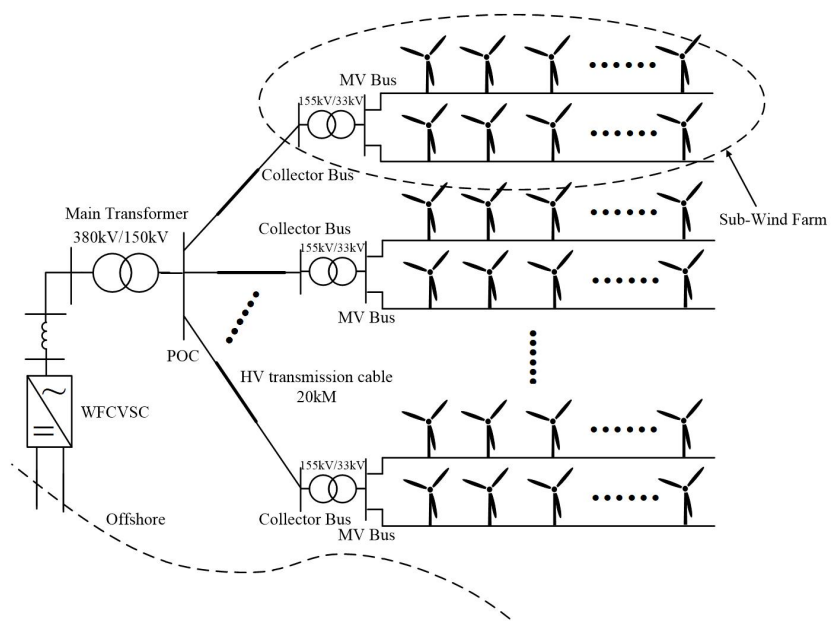

Fig. 1. Configuration of a wind farm.

\section{B. Control Concept}

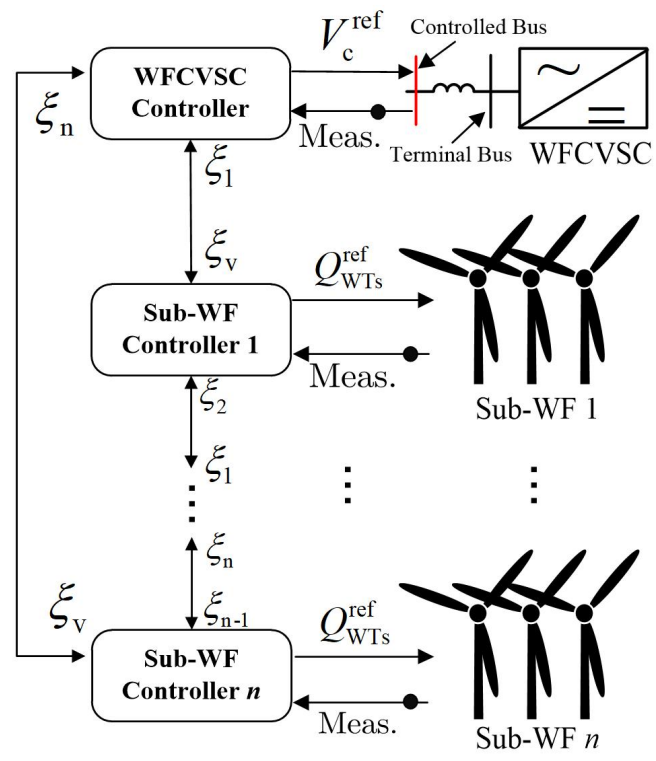

Fig. 2. Control structure.

Fig. 2 shows the control structure of the scheme. The WFCVSC is equipped with a WFCVSC controller and each sub-WF is equipped with a sub-WF controller. The WFCVSC 
controller generates an optimal voltage reference for the controlled bus while minimizing the voltage fluctuations of the POC and regulating the voltage of POC close to the rated value. The sub-WF controllers generate the optimal reactive power references for their corresponding WTs. The aims are to minimize the voltage fluctuations of the collector buses and WT terminal buses while regulating the bus voltages close to the rated value and smooth the reactive power outputs of the WTs inside the sub-WF. The WFCVSC controller and sub-WF controllers are operated in a distributed manner. The updated shared control variable vector is exchanged between the neighboring controllers, which are described in Section IV in detail. The optimization subproblem is solved in each sub-controller with local constraints and local measurements while guaranteeing the optimality of the primal optimization problem. A ring communication topology is used in the WFC, which considers the $N-1$ principle.

\section{Voltage CONTROL OF LARGE-SCALE WFC}

\section{A. WFCVSC and WT model}

The WFCVSC is used to regulate the voltage magnitude and frequency of the WFC AC grid while transmitting power from the AC side to the DC side. Based on [12], [17], the control diagram of the WFCVSC is shown in Fig. 3.

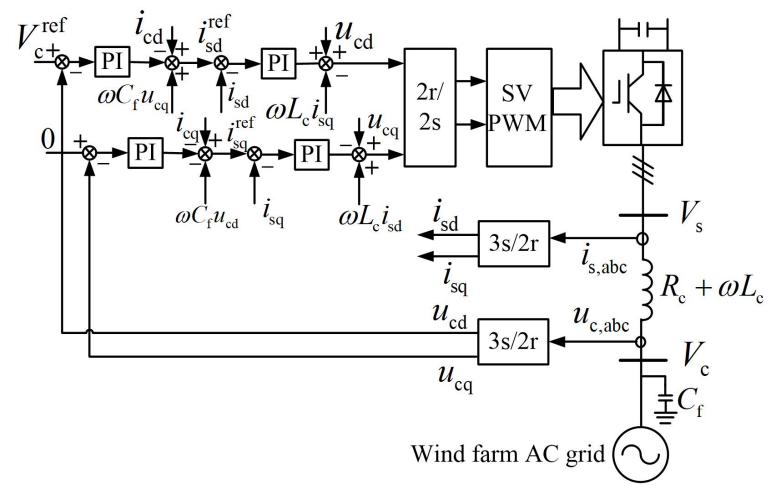

Fig. 3. Control diagram of the WFCVSC.

In Fig. 3, $V_{\mathrm{c}}$ is the controlled $\mathrm{AC}$ bus voltage, $V_{\mathrm{s}}$ is the terminal voltage of the WFCVSC, which can be seen as the slack bus of the WFC, and the phase reactor is represented by $R_{\mathrm{c}}+L_{\mathrm{c}}$. The operation of the WFCVSC is achieved by using a standard cascaded control structure, which includes an inner current control loop and an outer voltage control loop. Since the d-axis of the reference frame is oriented along the voltage-oriented vector of the WFC AC grid, $V_{\mathrm{c}} \approx u_{\mathrm{cd}}$, and $u_{\mathrm{cq}}=0$. Since the time constant of the outer voltage loop is much lager than that of the inner current loop, the inner current loop can be modeled as a first-order lag function by selecting suitable parameters of the PI controller. Thus, the WFCVSC control diagram is shown in Fig. 4.

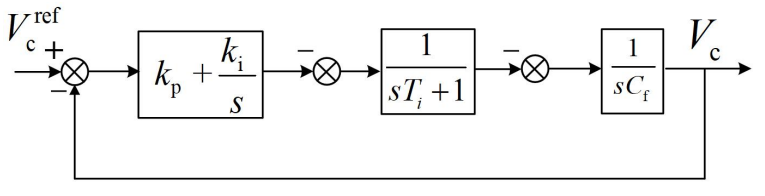

Fig. 4. Control diagram of the WFCVSC.

Define $V_{\mathrm{c}}^{\text {ref }}$ and $V_{\mathrm{c}}$ as the voltage reference and measurement of the controlled AC bus, respectively, $K_{\mathrm{P}}$ and $K_{\mathrm{i}}$ as the proportional and integral gains of the PI controller of the outer voltage control loop, respectively, $i_{\mathrm{sd}}$ as the d-axis current of the WFCVSC, $V_{\mathrm{c}}^{\text {int }}$ as the integral of the error between $V_{\mathrm{c}}^{\text {ref }}$ and $V_{\mathrm{c}}, C_{\mathrm{f}}$ as the capacitance, $T_{\mathrm{i}}$ as the time constant of the inner current loop, and $\Delta$ stands for the incremental operator. Thus, the incremental state-space model of the WFCVSC in the matrix form can be represented as,

$$
\Delta \dot{x}_{\mathrm{v}}=\boldsymbol{A}_{\mathrm{v}} \Delta x_{\mathrm{v}}+\boldsymbol{B}_{\mathrm{v}} \Delta u_{\mathrm{v}}
$$

where

$$
\begin{gathered}
\Delta x_{\mathrm{v}}=\left[\Delta V_{\mathrm{c}}, \Delta V_{\mathrm{c}}^{\mathrm{int}}, \Delta i_{\mathrm{sd}}\right]^{\mathrm{T}}, \Delta u_{\mathrm{t}}=V_{\mathrm{c}}^{\mathrm{ref}} \\
\boldsymbol{A}_{\mathrm{v}}=\left[\begin{array}{ccc}
0 & 0 & -\frac{1}{C_{\mathrm{f}}} \\
-1 & 0 & 0 \\
\frac{K_{\mathrm{p}}}{T_{\mathrm{i}}} & -\frac{K_{\mathrm{i}}}{T_{\mathrm{i}}} & -\frac{1}{T_{\mathrm{i}}}
\end{array}\right] \boldsymbol{B}_{\mathrm{v}}=\left[\begin{array}{c}
0 \\
1 \\
\frac{K_{\mathrm{p}}}{T_{\mathrm{i}}}
\end{array}\right]
\end{gathered}
$$

With power electronic converters, the WTs can regulate active power and reactive power independently. The WTs can provide reactive power support for the power system and regulate the bus voltages inside the WFC while operating in the maximal power point tracking (MPPT) mode. According to [23], the dynamic response of the WT converter can be modeled as a first-order transfer function by considering perfect control decoupling between the active and reactive power. Then, considering the time delay of the communication system and dynamic reactive power response of the WT, the dynamic behavior of WT reactive power output can be obtained as,

$$
\Delta Q_{\mathrm{wt}}=\frac{1}{1+s T_{\mathrm{Q}}} \Delta Q_{\mathrm{wt}}^{\mathrm{ref}}
$$

where $Q_{\mathrm{wt}}$ is the reactive power output of the WT, $Q_{\mathrm{wt}}^{\mathrm{ref}}$ is the reactive power reference of the $\mathrm{WT}$, and $T_{\mathrm{Q}}$ is the time constant of the reactive power dynamic behavior of the WT. Then, we can obtain,

$$
\Delta \dot{Q}_{\mathrm{wt}}=-\frac{1}{T_{\mathrm{Q}}} \Delta Q_{\mathrm{wt}}+\frac{1}{T_{\mathrm{Q}}} \Delta Q_{\mathrm{wt}}^{\mathrm{ref}}
$$

\section{B. Objective Function}

In the conventional optimal voltage control problem, the voltage sensitivity coefficients can be obtained from the updated Jacobian matrix, which has to be rebuilt and inverted for every change in the operational conditions of the network. Moreover, this method cannot be used to calculate the sensitivity coefficients with respect to the slack bus voltage. To avoid the above issues and improve the computational efficiency, the analytical voltage sensitivity calculation method in [24] is used to formulate the objective function. Once the voltage sensitivity with respect to active and reactive power injections of the 
WTs and slack bus voltage are obtained, the first objective function can be formulated. The aims of the first objective function are to minimize the voltage fluctuations of the POC, collector buses, and WT terminal buses while regulating the bus voltages close to the rated voltage. Moreover, the power losses of the WFC network can also be reduced efficiently by regulating the voltage profile across the WFC network [25]. Then, the first objective function can be expressed as,

$$
\begin{gathered}
O b j_{1}=\min \left\|V_{\text {POC }}-V_{\text {rated }}\right\|_{Q_{\mathrm{p}}}^{2}+\sum_{i=1}^{\left|\mathcal{N}_{\mathrm{C}}\right|}\left\|V_{\mathrm{cb}, i}-V_{\text {rated }}\right\|_{Q_{\mathrm{c}}}^{2} \\
+\sum_{i=1}^{\left|\mathcal{N}_{\mathrm{wt}}\right|}\left\|V_{\mathrm{wt}, i}-V_{\text {rated }}\right\|_{Q_{\mathrm{w}}}^{2}
\end{gathered}
$$

where $\mathcal{N}_{\mathrm{C}}$ is the set of the collector buses, $\mathcal{N}_{\mathrm{wt}}$ is the set of the WT terminal buses, $Q_{\mathrm{p}}, Q_{\mathrm{c}}$ and $Q_{\mathrm{w}}$ are the weighting factors for minimizing the fluctuations of the POC, collector buses, and WT terminal buses, respectively, $V_{\mathrm{POC}}$ is the voltage of the POC, $V_{\mathrm{cb}, i}$ is the voltage of the $i$ th collector bus, $V_{\mathrm{wt}, i}$ is the voltage of the $i$ th WT terminal bus, and $V_{\text {rated }}$ is the rated voltage of the WFC. In each control period, $V_{\mathrm{POC}}, V_{\mathrm{cb}, i}$, and $V_{\mathrm{wt}, i}$ can be described by,

$$
\begin{aligned}
V_{\mathrm{POC}} & =V_{\mathrm{POC}}^{0}+\frac{\partial V_{\mathrm{POC}}}{\partial V_{\mathrm{s}}} \Delta V_{\mathrm{s}}+\frac{\partial V_{\mathrm{POC}}}{\partial Q_{\mathrm{wt}}} \Delta Q_{\mathrm{wt}} \\
V_{\mathrm{cb}, i} & =V_{\mathrm{cb}}^{0}+\frac{\partial V_{\mathrm{cb}, i}}{\partial V_{\mathrm{s}}} \Delta V_{\mathrm{s}}+\frac{\partial V_{\mathrm{cb}, i}}{\partial Q_{\mathrm{wt}}} \Delta Q_{\mathrm{wt}}, \quad \forall i \in \mathcal{N}_{\mathrm{C}} \\
V_{\mathrm{wt}, i} & =V_{\mathrm{wt}}^{0}+\frac{\partial V_{\mathrm{wt}, i}}{\partial V_{\mathrm{s}}} \Delta V_{\mathrm{s}}+\frac{\partial V_{\mathrm{wt}, i}}{\partial Q_{\mathrm{wt}, i}} \Delta Q_{\mathrm{wt}}, \quad \forall i \in \mathcal{N}_{\mathrm{wt}}
\end{aligned}
$$

with

$$
\begin{gathered}
\frac{\partial V_{\mathrm{POC}}}{\partial Q_{\mathrm{wt}}}=\left[\frac{\partial V_{\mathrm{POC}}}{\partial Q_{\mathrm{wt}, i}}, \frac{\partial V_{\mathrm{POC}}}{\partial Q_{\mathrm{wt}, 2}}, \cdots, \frac{\partial V_{\mathrm{POC}}}{\partial Q_{\mathrm{wt},\left|\mathcal{N}_{\mathrm{wt}}\right|}}\right], \\
\frac{\partial V_{\mathrm{cb}, i}}{\partial Q_{\mathrm{wt}}}=\left[\frac{\partial V_{\mathrm{cb}, i}}{\partial Q_{\mathrm{wt}, 1}}, \frac{\partial V_{\mathrm{cb}, i}}{\partial Q_{\mathrm{wt}, 2}}, \cdots, \frac{\partial V_{\mathrm{cb}, i}}{\partial Q_{\mathrm{wt},\left|\mathcal{N}_{\mathrm{wt}}\right|}}\right], \\
\frac{\partial V_{\mathrm{wt}, i}}{\partial Q_{\mathrm{wt}}}=\left[\frac{\partial V_{\mathrm{wt}, i}}{\partial Q_{\mathrm{wt}, 1}}, \frac{\partial V_{\mathrm{wt}, i}}{\partial Q_{\mathrm{wt}, 2}}, \cdots, \frac{\partial V_{\mathrm{wt}, i}}{\partial Q_{\mathrm{wt},\left|\mathcal{N}_{\mathrm{wt}}\right|}}\right], \\
Q_{\mathrm{wt}}=\left[Q_{\mathrm{wt}, 1}, Q_{\mathrm{wt}, 2}, Q_{\mathrm{wt}, 3}, \cdots, Q_{\mathrm{wt},\left|\mathcal{N}_{\mathrm{wt}}\right|}\right]^{T},
\end{gathered}
$$

In order to facilitate the long-term stable operation of the generators and converters inside the WFC, the aim of the second control objective is to smooth the reactive power outputs of the WTs, which can be expressed as,

$$
O b j_{2}=\min \sum_{i=1}^{\left|\mathcal{N}_{\mathrm{wt}}\right|}\left\|Q_{\mathrm{wt}, i}-Q_{\mathrm{wt}, i}^{0}\right\|_{Q_{\mathrm{R}}}^{2}
$$

where $Q_{\mathrm{wt}, i}^{0}$ is the initial reactive power output of the $i$ th WT in a control period, and $Q_{\mathrm{R}}$ is the weighting factor. Combining (4) and (8), the total objective function of the WFC can be obtained as,

$$
F_{\mathrm{WFC}}=O b j_{1}+O b j_{2}
$$

For a WT, the reactive power output of the WT cannot exceed the available reactive power capacity of the WT,

$$
Q_{\mathrm{wt}, i}^{\min } \leq Q_{\mathrm{wt}, i} \leq Q_{\mathrm{wt}, i}^{\max } .
$$

where $Q_{\mathrm{wt}, i}^{\min }$ and $Q_{\mathrm{wt}, i}^{\max }$ are the minimal and maximal available reactive power of the $i$ th WT, respectively. For the WFCVSC, the controlled voltage should be kept within a feasible range,

$$
V_{\mathrm{c}}^{\min } \leq V_{\mathrm{c}} \leq V_{\mathrm{c}}^{\max }
$$

where $V_{\mathrm{c}}^{\min }$ and $V_{\mathrm{c}}^{\max }$ are the minimal and maximal voltages of the controlled bus, respectively.

\section{Distributed Solution Method Based on ATC}

In the large-scale WFC voltage control, each bus voltage is affected by the reactive power injections from all WTs inside the WFC. In the conventional centralized-based voltage control methods, the WFC central controller must gather all the required measurements from all WTs and buses, as well as the whole voltage sensitivity coefficients to obtain the optimal solution for the WFC. With the development of large-scale wind power projects, the centralized optimization algorithms might not be suitable for the large systems. Therefore, an ATC based distributed solution method is proposed in this section to solve the large-scale strongly coupled optimization problem separately and restore the optimality and adaptability through an iterative message-passing algorithm.

\section{A. Optimization Problem of the WFCVSC Controller}

The large-scale optimization problem can be decomposed into several optimization subproblems and distributed to the WFCVSC controller and several sub-WF controllers. Since the WFCVSC controller is close to the POC, the optimization subproblem of the WFCVSC is to minimize the voltage fluctuations of the POC by optimizing the controlled bus voltage reference and reactive power output of the sub-WFs. For the WFCVSC controller, it is assumed that each sub-WF is equivalent to a current source, injecting active and reactive power to the collector bus. Thus, the equivalent configuration of the WFC for the WFCVSC controller is shown in Fig. 5.

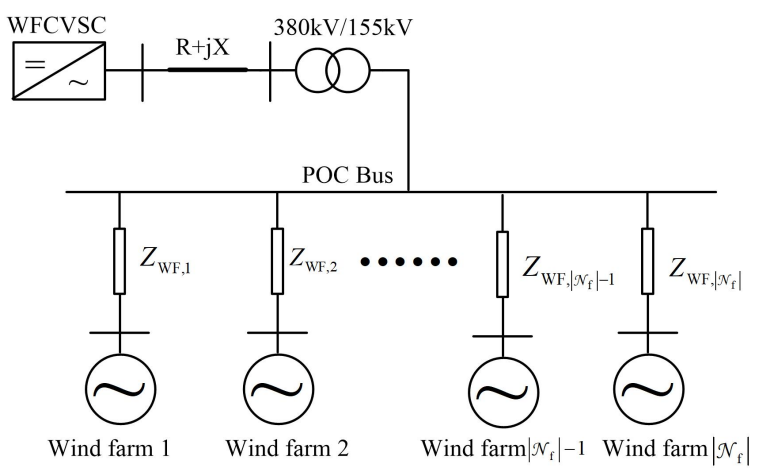

Fig. 5. Equivalent configuration of the WFC for the WFCVSC controller.

Denote $\mathcal{N}_{\mathrm{f}}$ as the set of the sub-WFs inside the WFC and the incremental state-space model of the WFC for the WFCVSC controller in the matrix form can be represented as,

$$
\begin{aligned}
\Delta \dot{x}_{\mathrm{wv}} & =\boldsymbol{A}_{\mathrm{wv}} \Delta x_{\mathrm{wv}}+\boldsymbol{B}_{\mathrm{wv}} \Delta u_{\mathrm{wv}} \\
\Delta y_{\mathrm{wv}} & =\boldsymbol{C}_{\mathrm{wv}} \Delta x_{\mathrm{wv}}
\end{aligned}
$$


where

$$
\begin{aligned}
& \Delta x_{\mathrm{wv}}=\left[\Delta x_{\mathrm{v}}, \Delta Q_{\mathrm{wf}, 1}, \Delta Q_{\mathrm{wf}, 2}, \cdots, \Delta Q_{\mathrm{wf},\left|\mathcal{N}_{\mathrm{f}}\right|}\right]^{\mathrm{T}}, \\
& \Delta u_{\mathrm{wv}}=\left[\Delta V_{\mathrm{c}}^{\mathrm{ref}(\mathrm{v})}, \Delta Q_{\mathrm{wf}, 1}^{\mathrm{ref}(\mathrm{v})}, \Delta Q_{\mathrm{wf}, 2}^{\mathrm{ref}(\mathrm{v})}, \cdots, \Delta Q_{\mathrm{wf},\left|\mathcal{N}_{\mathrm{f}}\right|}^{\mathrm{ref}(\mathrm{v})}\right]^{\mathrm{T}}, \\
& \Delta y_{\mathrm{wv}}=\left[\Delta V_{\mathrm{s}}^{(\mathrm{v})}, \Delta Q_{\mathrm{wf}, 1}^{(\mathrm{v})}, \Delta Q_{\mathrm{wf}, 2}^{(\mathrm{v})}, \cdots, \Delta Q_{\mathrm{wf},\left|\mathcal{N}_{\mathrm{f}}\right|}^{(\mathrm{v})}\right]^{\mathrm{T}}, \\
& \boldsymbol{A}_{\mathrm{wv}}=\left[\begin{array}{ll}
\boldsymbol{A}_{\mathrm{v}} & \\
& \boldsymbol{A}_{\mathrm{wf}}^{\mathrm{v}}
\end{array}\right] \boldsymbol{B}_{\mathrm{wv}}=\left[\begin{array}{ll}
\boldsymbol{B}_{\mathrm{v}} & \\
& \boldsymbol{B}_{\mathrm{wf}}^{\mathrm{v}}
\end{array}\right] \\
& \boldsymbol{C}_{\mathrm{wv}}=\left[\begin{array}{cccc}
\boldsymbol{C}_{\mathrm{v}} & \boldsymbol{C}_{\mathrm{cb}, 1} & \cdots & \boldsymbol{C}_{\mathrm{cb},\left|\mathcal{N}_{\mathrm{f}}\right|} \\
& 1_{1} & & \\
& & \ddots & \\
& & & 1_{\left|\mathcal{N}_{\mathrm{f}}\right|}
\end{array}\right]
\end{aligned}
$$

with

$$
\begin{gathered}
\boldsymbol{A}_{\mathrm{wf}}^{\mathrm{v}}=\operatorname{diag}\left[-\frac{1}{T_{\mathrm{Q}, 1}},-\frac{1}{T_{\mathrm{Q}, 2}}, \cdots,-\frac{1}{T_{\mathrm{Q},\left|\mathcal{N}_{\mathrm{f}}\right|}}\right], \\
\boldsymbol{B}_{\mathrm{wf}}^{\mathrm{v}}=\operatorname{diag}\left[\frac{1}{T_{\mathrm{Q}, 1}}, \frac{1}{T_{\mathrm{Q}, 2}}, \cdots, \frac{1}{T_{\mathrm{Q},\left|\mathcal{N}_{\mathrm{f}}\right|}}\right] \\
\boldsymbol{C}_{\mathrm{v}}=-\left(\frac{\partial V_{\mathrm{c}}}{\partial V_{\mathrm{s}}}\right)^{-1}[-1,0,0] \\
\boldsymbol{C}_{\mathrm{cb}, i}=-\left(\frac{\partial V_{\mathrm{c}}}{\partial V_{\mathrm{s}}}\right)^{-1}\left(\frac{\partial V_{\mathrm{c}}}{\partial Q_{\mathrm{cb}, i}}\right), \quad \forall i \in \mathcal{N}_{\mathrm{C}}
\end{gathered}
$$

where $V_{\mathrm{c}}^{\mathrm{ref}(\mathrm{v})}$ is the controlled bus voltage reference optimized in the WFCVSC controller, $Q_{\mathrm{wf}, i}^{\mathrm{ref}(\mathrm{v})}$ is the total reactive power reference of the $i$ th sub-WF optimized in the WFCVSC controller, and $\frac{\partial V_{\mathrm{c}}}{\partial Q_{\mathrm{cb}, i}}$ is the controlled bus voltage sensitivity with respect to the reactive power injection from the $i$ th subWF collector bus. According to (12) and (13), the objective function of the WFCVSC is,

$$
\begin{gathered}
f_{\mathrm{vsc}}=\min \left\|V_{\mathrm{POC}}-V_{\text {rated }}\right\|_{Q_{\mathrm{p}}}^{2} \\
\text { s.t. } \quad(11)
\end{gathered}
$$

with

$$
\begin{gathered}
V_{\mathrm{POC}}=V_{\mathrm{POC}}^{0}+\frac{\partial V_{\mathrm{POC}}}{\partial y} \Delta y_{\mathrm{wv}} \\
\frac{\partial V_{\mathrm{POC}}}{\partial y}=\left[\frac{\partial V_{\mathrm{POC}}}{\partial V_{\mathrm{s}}}, \frac{\partial V_{\mathrm{POC}}}{\partial Q_{\mathrm{cb}, i}}, \frac{\partial V_{\mathrm{POC}}}{\partial Q_{\mathrm{cb}, 2}}, \cdots, \frac{\partial V_{\mathrm{POC}}}{\partial Q_{\mathrm{cb},\left|\mathcal{N}_{\mathrm{f}}\right|}}\right] .
\end{gathered}
$$

\section{B. Optimization Problem of the Sub-WF Controller}

The aims of each sub-WF controller are to minimize the voltage fluctuations of the corresponding collector bus and WT terminal buses and smooth the reactive power outputs of the WTs inside the sub-WF. The equivalent configuration of the WFC for the $i$ th sub-WF controller is shown in Fig. 6.

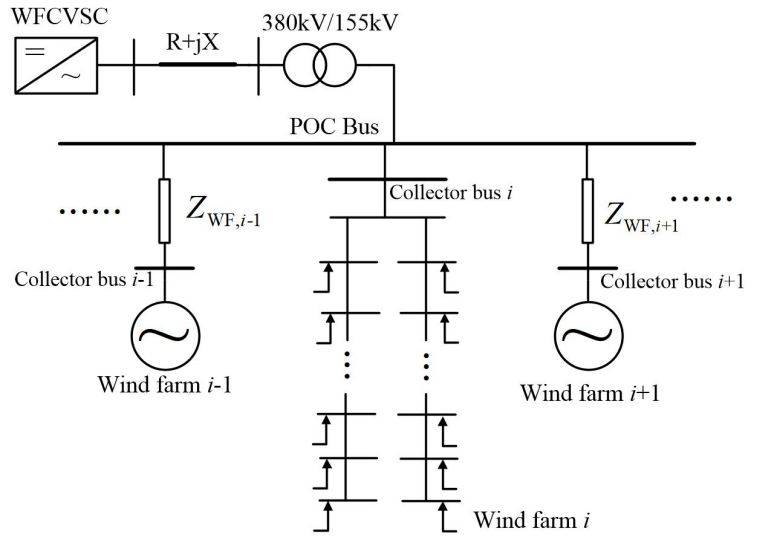

Fig. 6. Equivalent configuration of the WFC for the WFCVSC controller.

Denote $\mathcal{N}_{\mathrm{f}}^{(i)}$ as the set of the sub-WFs inside the WFC except the $i$ th sub-WF, and $\mathcal{N}_{\mathrm{wt}}^{(i)}$ as the set of the WTs inside the $i$ th sub-WF, the incremental state-space model of the WFC for the $i$ th sub-WF controller in the matrix form can be represented as,

$$
\begin{aligned}
\Delta \dot{x}_{i} & =\boldsymbol{A}_{i} \Delta x_{i}+\boldsymbol{B}_{i} \Delta u_{i} \\
\Delta y_{i} & =\boldsymbol{C}_{i} \Delta x_{i}
\end{aligned}
$$

where

$$
\begin{gathered}
\Delta x_{i}=\left[\Delta x_{\mathrm{v}}, \Delta Q_{\mathrm{wf}, 1}, \cdots, \Delta Q_{\mathrm{wf},\left|\mathcal{N}_{\mathrm{f}}^{(i)}\right|}, \Delta Q_{\mathrm{wt}, 1}, \cdots, \Delta Q_{\mathrm{wt},\left|\mathcal{N}_{\mathrm{wt}}^{(i)}\right|}\right]^{\mathrm{T}}, \\
\Delta u_{i}=\left[\Delta V_{\mathrm{c}}^{\mathrm{ref}(i)}, \Delta Q_{\mathrm{wf}, 1}^{\operatorname{ref}(i)}, \cdots, \Delta Q_{\mathrm{wf},\left|\mathcal{N}_{\mathrm{f}}^{(i)}\right|}^{\operatorname{ref}(i)}, \Delta Q_{\mathrm{wt}, 1}^{\operatorname{ref}(i)}, \cdots, \Delta Q_{\mathrm{wt},\left|\mathcal{N}_{\mathrm{wt}}^{(i)}\right|}^{\operatorname{ref}(i)}\right]^{\mathrm{T}},
\end{gathered}
$$$$
\Delta y_{i}=\left[\Delta V_{\mathrm{s}}^{(\mathrm{i})}, \Delta Q_{\mathrm{wf}, 1}, \cdots, \Delta Q_{\mathrm{wf},\left|\mathcal{N}_{\mathrm{f}}^{(i)}\right|}, \Delta Q_{\mathrm{wt}, 1}, \cdots, \Delta Q_{\mathrm{wt},\left|\mathcal{N}_{\mathrm{wt}}^{(i)}\right|}\right]^{\mathrm{T}},
$$$$
\boldsymbol{A}_{i}=\left[\begin{array}{ll}
\boldsymbol{A}_{\mathrm{v}} & \\
& \boldsymbol{A}_{\mathrm{wf}}^{i}
\end{array}\right] \boldsymbol{B}_{i}=\left[\begin{array}{ll}
\boldsymbol{B}_{\mathrm{v}} & \\
& \boldsymbol{B}_{\mathrm{wf}}^{i}
\end{array}\right] \boldsymbol{C}_{i}=\left[\begin{array}{ll}
\boldsymbol{C}_{\mathrm{v}} & \boldsymbol{C}_{1} \\
\boldsymbol{C}_{2} & \boldsymbol{C}_{3}
\end{array}\right]
$$$$
\boldsymbol{C}_{1}=\left[\boldsymbol{C}_{\mathrm{cb}, 1}, \cdots, \boldsymbol{C}_{\mathrm{cb},\left|\mathcal{N}_{\mathrm{f}}^{(i)}\right|}, \boldsymbol{C}_{\mathrm{wt}, 1}, \cdots, \boldsymbol{C}_{\mathrm{wt},\left|\mathcal{N}_{\mathrm{f}}^{(i)}\right|}\right]
$$$$
\boldsymbol{C}_{2}=0^{\alpha \times 3}, \boldsymbol{C}_{3}=I^{\alpha \times \alpha}, \alpha=\left|\mathcal{N}_{\mathrm{f}}^{(i)}\right|+\left|\mathcal{N}_{\mathrm{wt}}^{(i)}\right|
$$

with

$$
\begin{gathered}
\boldsymbol{A}_{\mathrm{wf}}^{i}=\operatorname{diag}\left[-\frac{1}{T_{\mathrm{Q}, 1}},-\frac{1}{T_{\mathrm{Q}, 2}}, \cdots,-\frac{1}{T_{\mathrm{Q},\left|\mathcal{N}_{\mathrm{f}}^{(i)}\right|+\left|\mathcal{N}_{\mathrm{wt}}^{(i)}\right|}}\right], \\
\boldsymbol{B}_{\mathrm{wf}}^{i}=\operatorname{diag}\left[\frac{1}{T_{\mathrm{Q}, 1}}, \frac{1}{T_{\mathrm{Q}, 2}}, \cdots, \frac{1}{\left.T_{\mathrm{Q},\left|\mathcal{N}_{\mathrm{f}}^{(i)}\right|+\left|\mathcal{N}_{\mathrm{wt}}^{(i)}\right|}\right],}\right. \\
\boldsymbol{C}_{\mathrm{wt}, i}=-\left(\frac{\partial V_{\mathrm{c}}}{\partial V_{\mathrm{s}}}\right)^{-1}\left(\frac{\partial V_{\mathrm{c}}}{\partial Q_{\mathrm{wt}, i}}\right), \quad \forall i \in \mathcal{N}_{\mathrm{wt}}^{(i)}
\end{gathered}
$$

where $V_{\mathrm{c}}^{\mathrm{ref}(i)}$ is the controlled bus voltage reference optimized in the $i$ th sub-WF controller, $Q_{\mathrm{wf}, j}^{\mathrm{ref}(i)}$ is the total reactive power reference of the $j$ th sub-WF optimized in the $i$ th sub-WF controller, and $Q_{\mathrm{wt}, i}^{\mathrm{ref}(i)}$ is the reactive power reference of the 
$i$ th WT optimized in the $i$ th sub-WF controller. The objective function of the $i$ th sub-WF controller is,

$$
\begin{gathered}
f_{i}=\min \left\|V_{\mathrm{cb}, i}-V_{\text {rated }}\right\|_{Q_{\mathrm{c}}}^{2}+\sum_{i=1}^{\left|\mathcal{N}_{\mathrm{wt}}^{(i)}\right|}\left\|V_{\mathrm{wt}, i}-V_{\text {rated }}\right\|_{Q_{\mathrm{w}}}^{2} \\
+\sum_{i=1}^{\left|\mathcal{N}_{\mathrm{wt}}^{(i)}\right|}\left\|Q_{\mathrm{wt}, i}-Q_{\mathrm{wt}, i}^{0}\right\|_{Q_{\mathrm{R}}}^{2} \\
\text { s.t. } \quad Q_{\mathrm{wt}, i}^{\min } \leq Q_{\mathrm{wt}, i} \leq Q_{\mathrm{wt}, i}^{\max }, \quad \forall i \in \mathcal{N}_{\mathrm{wt}}^{(i)} .
\end{gathered}
$$

The line constraints also can be considered into the optimization sub-problem. Define $\mathcal{N}_{\mathrm{L}}^{(i)}$ as the set of cables of the $i$ th sub-WF and $\mathcal{N}_{\mathrm{B}}^{(i)}$ as the set of buses of the $i$ th sub-WF. Then we can obtain,

$$
V_{\mathrm{wf}}=V_{\mathrm{wf}}^{0}+S \Delta y_{i}
$$

where $V_{\mathrm{wf}}=\left[V_{1}, V_{2}, V_{3}, V_{4}, \ldots V_{\left|\mathcal{N}_{\mathrm{L}}^{(i)}\right|}\right]^{T}, V_{\mathrm{wf}}^{0}=\left[V_{1}^{0}, V_{2}^{0}, V_{3}^{0}\right.$, $\left.V_{4}^{0}, \ldots V_{\left|\mathcal{N}_{\mathrm{L}}^{(i)}\right|}^{0}\right]^{T}$, and $S$ is the voltage sensitivity coefficient matrix related to $\Delta y_{i}$. Then, we can get,

$$
I_{\mathrm{wf}}=G_{\mathrm{wf}, i} V_{\mathrm{wf}}
$$

where $I_{\mathrm{wf}}=\left[I_{1}, I_{2}, I_{3}, I_{4}, \ldots I_{\left|\mathcal{N}_{\mathrm{B}}^{(i)}\right|}\right]^{T}$, and $G_{\mathrm{wf}, i}$ is the real part of the admittance matrix of the $i$ th sub-WF. Thus, the line constraints are obtained as,

$$
I_{i}^{\min } \leq I_{i} \leq I_{i}^{\max }, \quad \forall i \in \mathcal{N}_{\mathrm{L}}^{(i)} .
$$

where $I_{i}^{\min }$ and $I_{i}^{\max }$ are the minimal and maximal current limits of the $i$ th cable inside the sub-WF, respectively.

\section{ATC-Based Solution Method}

According to Sections III. A and B, the sum of the objective function of the sub-controllers is equal to the primal objective function of the WFC controller,

$$
f_{\mathrm{vsc}}+\sum_{i=1}^{\left|\mathcal{N}_{\mathrm{f}}\right|} f_{i}=F_{\mathrm{WFC}}
$$

Each sub-controller has local control variables and shared control variables with other sub-controllers. Based on the ATC method, the sub-controllers solve the optimization subproblems with their corresponding constraints in parallel while exchanging the value of the shared variables with their immediate neighbors. Once the value of the shared variables converges, the optimal solution of the primal optimization problem is obtained. Denote $\mathcal{V}$ as the set of the WFCVSC, and the optimization subproblem of the WFCVSC can be formulated in an augmented Lagrangian form,

$\min f_{\mathrm{vsc}}+\sum_{j \in \mathcal{N}_{\mathrm{f}} \cup \mathcal{V}} \tau_{v j}\left(\alpha_{v j}\left(\xi_{v}-\xi_{j}\right)+\left\|\beta_{v j} \circ\left(\left(\xi_{v}-\xi_{j}\right)\right)\right\|_{2}^{2}\right)$

where $\xi_{v}=\left[\Delta V_{\mathrm{c}}^{\mathrm{ref}(\mathrm{v})}, \Delta Q_{\mathrm{wf}, 1}^{\mathrm{ref}(\mathrm{v})}, \Delta Q_{\mathrm{wf}, 2}^{\mathrm{ref}(\mathrm{v})}, \cdots, \Delta Q_{\mathrm{wf},\left|\mathcal{N}_{\mathrm{f}}\right|}^{\mathrm{ref}(\mathrm{v})}\right]^{T}$ is the shared variable vector optimized in the WFCVSC controller, $\xi_{j}=\left[\Delta V_{\mathrm{c}}^{\operatorname{ref}(j)}, \Delta Q_{\mathrm{wf}, 1}^{\operatorname{ref}(j)}, \Delta Q_{\mathrm{wf}, 2}^{\operatorname{ref}(j)}, \cdots, \Delta Q_{\mathrm{wf},\left|\mathcal{N}_{\mathrm{f}}\right|}^{\operatorname{ref}(j)}\right]^{T}$ is the shared variable vector optimized in the $j$ th controller, and $\tau_{v j}$ is the adjacency coefficient. If there exists a directed communication path from the $i$ th controller to the $j$ th controller, $\tau_{i j}=1$, otherwise $\tau_{i j}=0, \alpha_{i j}$ and $\beta_{i j}$ are multipliers associated with the linear and quadratic terms, respectively, which are updated during the iterative solving process, and the operator $\circ$ is the Hadamard product. Similarly, the optimization subproblem of the $i$ th sub-WF controller can be formulated in an augmented Lagrangian form,

$$
\min f_{i}+\sum_{j \in \mathcal{N}_{\mathbf{f}} \cup \mathcal{V}} \tau_{i j}\left(\alpha_{i j}\left(\xi_{i}-\xi_{j}\right)+\left\|\beta_{i j} \circ\left(\left(\xi_{i}-\xi_{j}\right)\right)\right\|_{2}^{2}\right)
$$

To be noticed, the shared variable $\Delta Q_{\mathrm{wf}, i}^{\mathrm{ref}(\mathrm{i})}$ in $\xi_{i}$ is expressed as,

$$
\Delta Q_{\mathrm{wf}, i}^{\mathrm{ref}(\mathrm{i})}=\sum_{i=1}^{\left|\mathcal{N}_{\mathrm{wt}}^{(i)}\right|} \Delta Q_{\mathrm{wt}, i}
$$

With the ATC method, each sub-controller solves the local optimization problem with local measurements in a parallel manner. Taking the $i$ th sub-WF as an example, the solution procedures are illustrated as follows,

Step 1 : Choose initial values for $\alpha_{i j}$ and $\beta_{i j}$, and set the initial values of the iteration number $k, \xi_{i-1}$ and $\xi_{i+1}$ to zero.

Step 2 : Set $k=k+1$. Update the local control variables and shared control variables by using (22) with $\xi_{i-1}^{[k]}$ and $\xi_{i+1}^{[k]}$ from the $k$ th iteration,

$$
\begin{aligned}
\Delta u_{i}^{[k+1]}=\underset{\Delta u_{i}}{\arg \min } f_{i} & +\sum_{j \in \mathcal{N}_{\mathrm{f}} \cup \mathcal{V}} \tau_{i j}\left(\alpha_{i j}^{[k]}\left(\xi_{i}-\xi_{j}^{[k]}\right)\right. \\
& \left.+\left\|\beta_{i j}^{[k]} \circ\left(\xi_{i}-\xi_{j}^{[k]}\right)\right\|_{2}^{2}\right)
\end{aligned}
$$

with the constraints,

$$
Q_{\mathrm{wt}, i}^{\min } \leq Q_{\mathrm{wt}, i} \leq Q_{\mathrm{wt}, i}^{\max }, \quad \forall i \in \mathcal{N}_{\mathrm{wt}}^{(i)} .
$$

Step 3: Check the following necessary-consistency and sufficient conditions,

The necessary-consistency condition is,

$$
\begin{aligned}
& \xi_{i}^{[k+1]}-\xi_{i-1}^{[k]} \leq \varepsilon_{1} \\
& \xi_{i}^{[k+1]}-\xi_{i+1}^{[k]} \leq \varepsilon_{1}
\end{aligned}
$$

The sufficient condition is,

$$
\left|\frac{f_{i}\left(\Delta u_{i}^{[k+1]}\right)-f_{i}\left(\Delta u_{i}^{[k]}\right)}{f_{i}\left(\Delta u_{i}^{[k]}\right)}\right| \leq \varepsilon_{2}
$$

where $\varepsilon_{1}$ and $\varepsilon_{2}$ are coefficients. If the conditions are satisfied, set a variable as $\eta_{i}^{[k+1]}=1$, otherwise, $\eta_{i}^{[k+1]}=0$. Check the condition,

$$
\frac{\eta_{, i-1}^{[k]}+\eta_{i}^{[k+1]}+\eta_{, i+1}^{[k]}}{3}=1
$$

where $\eta_{i-1}^{[k]}$ and $\eta_{i+1}^{[k]}$ are sent from neighboring controllers with $\xi_{i-1}^{[k]}$ and $\xi_{i+1}^{[k]}$ at the same time. If the condition is satisfied, set $\eta_{\mathrm{all}, i}^{[k+1]}=1$, otherwise, $\eta_{\mathrm{all}, i}^{[k+1]}=0$. Go to step 4. 
Step 4 : Check the condition,

$$
\eta_{\mathrm{all}, i-1}^{[k]}=1, \eta_{\mathrm{all}, i}^{[k+1]}=1, \eta_{\mathrm{all}, i+1}^{[k]}=1
$$

If the conditions are not satisfied, go to step 5. Otherwise, the converged optimal result is obtained and the solution procedure stops.

Step 5 : Receive $\xi_{i-1}^{[k+1]}$ and $\xi_{i+1}^{[k+1]}$ from the neighboring controllers. Update the multipliers $\alpha_{i j}^{[k+1]}$ and $\beta_{i j}^{[k+1]}$ and return to step 2,

$$
\begin{gathered}
\alpha_{i j}^{[k+1]}=\alpha_{i j}^{[k]}+2\left(\beta_{i j}^{[k]}\right)^{2}\left(\xi_{i}^{[k+1]}-\xi_{j}^{[k+1]}\right) \\
\beta_{i j}^{[k+1]}=\lambda \beta_{i j}^{[k]}
\end{gathered}
$$

where $\lambda$ is a coefficient, which needs to be equal to or larger than one to obtain the converged optimal results. Although the sub-WF controller solves the optimal sub-problem with the local measurements and local constraints, the shared variables are optimized in each sub-controller in parallel. The primal optimization problem is formulated as an augmented Lagrangian form and decomposed to several subproblem. The shared variables will be optimized at each sub-controller in parallel by considering their corresponding local measurements and local constraints. The ATC-based algorithm is an iterative messagepassing algorithm. Each sub-controller exchanges the shared variables with their neighbor controllers. Once the values of the shared variables optimized in each sub-controller converge, the optimal solution of the primal optimization problem is obtained.

\section{CASE Study}

\section{A. Test System}

In this section, the WFC illustrated in Fig. 1 is used for the case study. The WFC consists of 5 sub-WFs and each sub-WF consists of $20 \times 5$ MW WTs. The total simulation time is set as $600 \mathrm{~s}$. The control action is carried out every $2 \mathrm{~s}$. Each sub-WF is operated in the MPPT mode under different wind conditions. To examine the performance of the proposed control method, the simulation results are compared with those based on a centralized optimal voltage control scheme (COVC), the twotier optimal voltage control (TT-OVC) scheme in [18], and a conventional PI control scheme. In the PI control scheme, a PI controller is used to generate a total reactive power reference to maintain the voltage of the POC close to the rated value. The reactive power references of the WTs are dispatched to the WTs based on a proportional distribution control scheme. The test system parameters of the WFC are shown in Table I.

\section{B. Control Performance}

Fig. 7 shows the total available active power of the WFC. From 0 to $250 \mathrm{~s}$, the available active power fluctuates around 360 MW. From 250 to $400 \mathrm{~s}$, the available active power increases to approximately $460 \mathrm{MW}$ gradually. From 400 to $600 \mathrm{~s}$, the available active power decreases to approximately 380 MW.

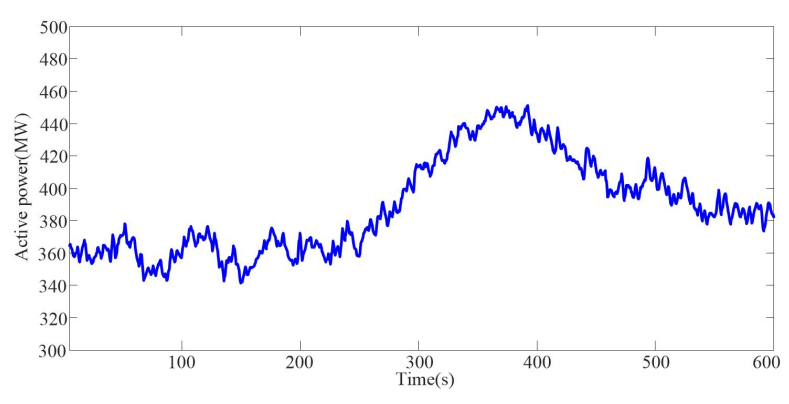

Fig. 7. Available wind power of the WFC.

The collector bus voltage of WF1 is shown in Fig. 8. The voltage with the PI control scheme fluctuates between 1.001 p.u. and 1.003 p.u.. From 0 to $250 \mathrm{~s}$, the voltage with the TTOVC scheme fluctuates between 0.9996 p.u. to 1.0008 p.u.. From 250 to $400 \mathrm{~s}$, the voltage fluctuates between 0.999 p.u. and 1 p.u. The voltage performances with the DOVC scheme are the same as those with the COVC scheme and are much better than those with the PI control scheme and TT-OVC scheme. The voltage fluctuates between 0.9998 p.u. and 1.0002 p.u. during the whole control period. Fig. 9 shows the voltage performances of the POC. The voltage of the POC is the only control objective of the PI control scheme. The POC voltage with the PI control scheme is controlled around 1 p.u., and the voltage of the POC with the remaining control schemes is controlled below 1 p.u.. The voltage fluctuations with the PI control scheme are larger than those with the other control schemes.

\begin{tabular}{|c|c|}
\hline $33 \mathrm{kV}$ Cable & $\begin{array}{l}R_{33 \mathrm{kV}}=0.078 \Omega / \mathrm{km}, L_{33 \mathrm{kV}}=0.3915 \mathrm{mH} / \mathrm{km}, \\
C_{33 \mathrm{kV}}=0.13 \mu \mathrm{F} / \mathrm{km}\end{array}$ \\
\hline $155 \mathrm{kV}$ Cable & $\begin{array}{l}R_{155 \mathrm{kV}}=0.0508 \Omega / \mathrm{km}, L_{155 \mathrm{kV}}=0.47 \mathrm{mH} / \mathrm{km}, \\
C_{155 \mathrm{kV}}=0.13 \mu \mathrm{F} / \mathrm{km}\end{array}$ \\
\hline $0.9 \mathrm{kV} / 33 \mathrm{kV}$ Transformer & $\begin{array}{l}S_{0.9 / 33 \mathrm{kV}}=5 \text { MVA, } R_{0.9} / 33 \mathrm{kV}=0.008 \text { p.u., } \\
L_{0.9 / 33 \mathrm{kV}}=0.06 \text { p.u. }\end{array}$ \\
\hline $33 \mathrm{kV} / 155 \mathrm{kV}$ Transformer & $\begin{array}{l}S_{33 / 155 \mathrm{kV}}=100 \mathrm{MVA}, R_{33 / 155 \mathrm{kV}}=0.006 \text { p.u., } \\
L_{33 / 155 \mathrm{kV}}=0.06 \text { p.u. }\end{array}$ \\
\hline $155 \mathrm{kV} / 380 \mathrm{kV}$ Transformer & $\begin{array}{l}S_{155 / 380 \mathrm{kV}}=500 \mathrm{MVA}, R_{155 / 380 \mathrm{kV}}=0.006 \text { p.u. } \\
L_{155 / 380 \mathrm{kV}}=0.06 \text { p.u. }\end{array}$ \\
\hline WFC rated capacity & $S_{\mathrm{WFC}}=500 \mathrm{MVA}$ \\
\hline Wind farm rated capacity & $S_{\mathrm{WF}}=100 \mathrm{MVA}$ \\
\hline WT rated capacity & $S_{\mathrm{WT}}=5 \mathrm{MVA}$ \\
\hline
\end{tabular}

TABLE I

TEST SYSTEM PARAMETERS

Fig. 10 shows the voltage performance of WT20, which is located at the end of the feeder of sub-WF1. The voltage performances with the TT-OVC scheme are much better than those with the PI control scheme. The voltage performances with the DOVC and COVC schemes are better than those with the TT-OVC scheme. The DOVC and COVC schemes can effectively control the voltage of the WT20 terminal bus within 1.002-1.005 p.u.. The zoomed part shows that the performances with the DOVC scheme are the same as those with the COVC scheme. The DOVC scheme guarantees the optimality of the primal centralized optimization problem. Fig. 


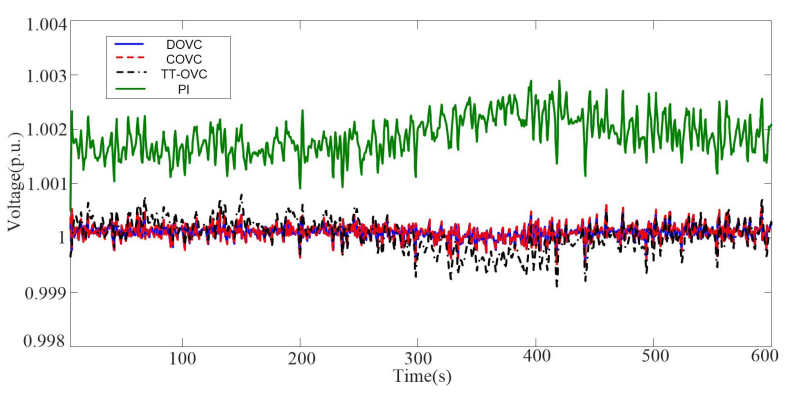

Fig. 8. Collector bus voltage of WF1.

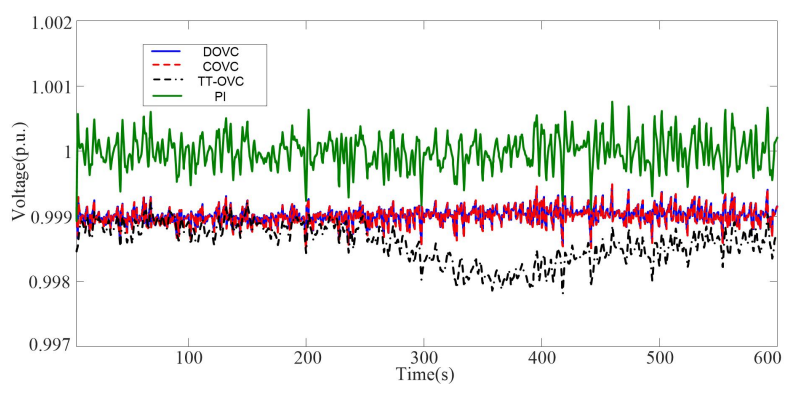

Fig. 9. POC voltage of the WFC.

11 shows that the overall voltage control performance, which shows the DOVC and COVC schemes are much better than the PI control and TT-OVC control schemes.

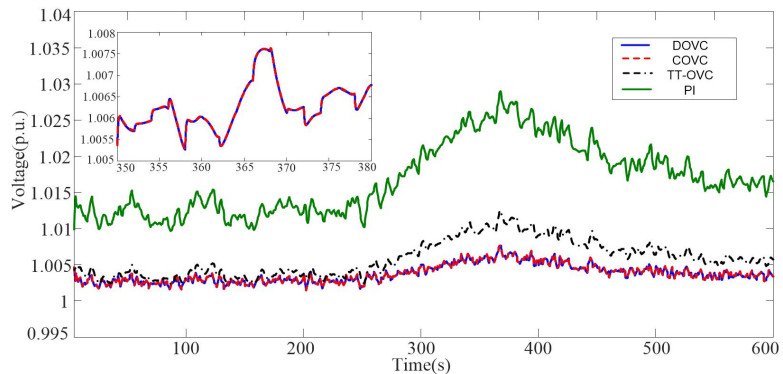

Fig. 10. Terminal bus voltage of WT20.

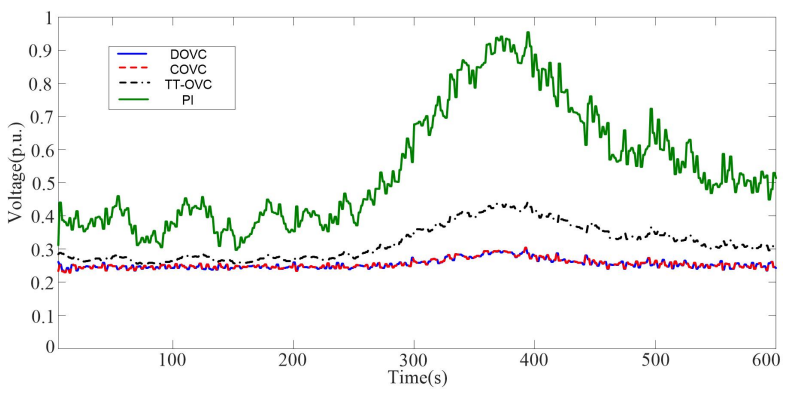

Fig. 11. Overall voltage control performance.

The reactive power output of WT20 is shown in Fig. 12. The reactive power outputs of the four control schemes are different. The reactive power output with the PI control scheme fluctuates from -0.6 to -0.4 MVar. The reactive power output with the TT-OVC scheme fluctuates from -1.4 to -1 MVar. The reactive power outputs with the DOVC and COVC schemes are the same, which fluctuates from -1.4 to $-1.2 \mathrm{MVar}$. The power losses of the WFC are shown in Fig. 13. The performances with the DOVC and COVC schemes are slightly better than those with the TT-OVC scheme and PI control scheme.

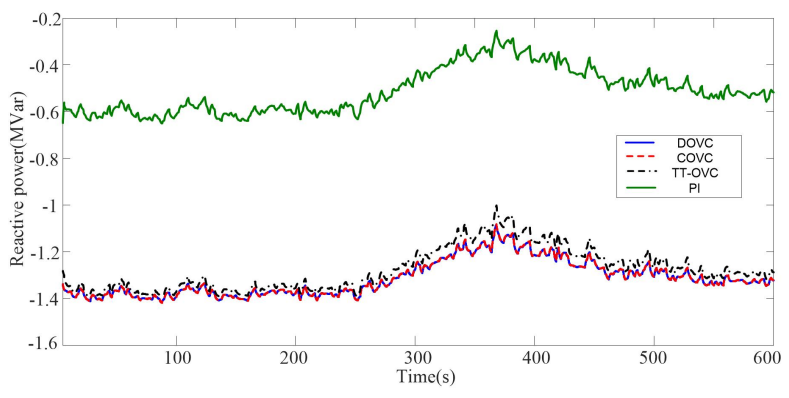

Fig. 12. Reactive power output of WT20

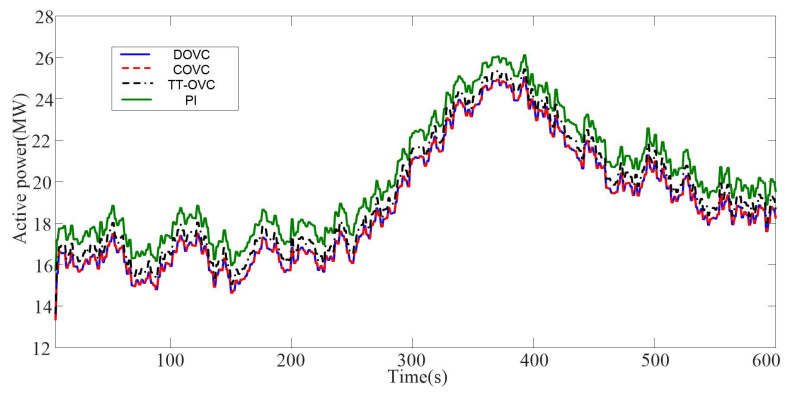

Fig. 13. Active power loss of the WFC.

The convergence performance with the ATC method is shown in Fig. 14. The active power references of the subWF3 and sub-WF5 optimized in the each sub-controllers are selected as the representative shared control variables to illustrate the performance of the convergence. The shared variables converge and remain constant at the same value after approximately 35 iterations, implying excellent convergence performance.

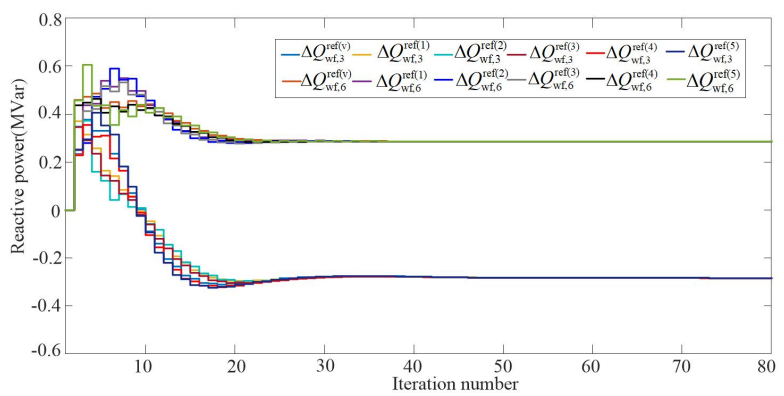

Fig. 14. Convergence performance.

Fig. 15 shows the current of the representative cable. The current of the cable between WT12 and WT13 are selected as the representative cable. The current of the cable with the PI control scheme reaches to approximately 0.02 p.u., which is much higher than those with the DOVC, COVC, and TT-OVC control schemes. 


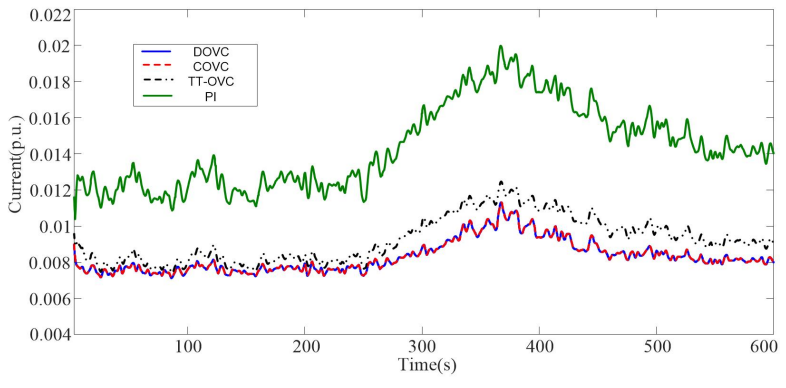

Fig. 15. Current of the representative cable.

\section{CONCLUSION}

In this paper, a DOVC scheme based on the ATC is proposed for the VSC-HVDC connected large-scale WFC. A voltagesensitivity-based optimization problem is formulated to minimize the voltage fluctuations of the POC, collector buses, and WT terminal buses while regulating the bus voltages close to the rated voltage and smooth the reactive power outputs of the WTs inside the WFC. A distributed solution method based on the ATC is proposed to solve the optimization problem in a parallel manner, which improves the reliability and scalability while protecting the information privacy of the WFC. As verified by case studies, the DOVC scheme can efficiently reduce the fluctuations of the POC, collector buses, and WT terminal buses and smooth the reactive power outputs of the WTs inside the WFC. The ATC-based distributed method achieves the same performance as a centralized control method and guarantees the optimality of the primal optimization problem. Due to its advantages with regard to scalability, flexibility, reliability and information privacy, the DOVC scheme is preferred for voltage control of the large-scale VSC-HVDC connected WFC.

\section{REFERENCES}

[1] N. Flourentzou, V. G. Agelidis, and G. D. Demetriades, "VSC-Based HVDC Power Transmission Systems: An Overview," IEEE Trans. Power Electron., vol. 3, no. 3, pp. 592-602, Mar. 2009.

[2] G. Zou, Q. Huang, S. Song, B. Tong, and H. Gao, "Novel transientenergy-based directional pilot protection method for HVDC line," Protection and Control of Modern Power Syst., vol. 2, no. 2, pp. 159-168, 2017.

[3] R. Zeng, L. Xu, L. Yao, S. J. Finney, and Y. Wang, "Hybrid HVDC for integrating wind farms with special consideration on commutation failure," IEEE Trans. Power Del., vol. 31, no. 2, pp. 789-797, Apr. 2016.

[4] P. Hou, W. Hu, M Soltani, C. Chen, B. Zhang, and Z. Chen, "Offshore wind farm layout design considering optimized power dispatch strategy," IEEE Trans. Sustain. Energy, vol. 8, no. 2, pp. 638-637, Apr. 2017.

[5] M. Mohseni and S. M. Islam, "Review of international grid codes for wind power integration: Diversity, technology and a case for global standard," Renew. Sustain. Energy Rev., vol. 16, pp. 3876-3890, Aug. 2012.

[6] P. K. Dash, R. K. Patnaik, and S. P. Mishra, "Adaptive fractional integral terminal sliding mode power control of UPFC in DFIG wind farm penetrated multimachine power system," Protection and Control of Modern Power Syst., vol. 3, no. 3, pp. 79-92, 2018.

[7] H. Zhao, Q. Wu, J. Wang, Z. Liu, M. Shahidehpour, and Y. Xue, "Combined active and reactive power control of wind farms based on model predictive control," IEEE Trans. Energy Conver, vol. 32, no. 3, pp. 1177-1187, Sep. 2017.

[8] H. Zhao, Q. Wu, Q. Guo, H. Sun, S. Huang, and Y. Xue, "Coordinated voltage control of a wind farm based on model predictive control," IEEE Trans. Sustain. Energy, vol. 7, no. 4, pp. 1440-1451, Oct. 2016.
[9] E. Sáiz-Marín, E. Lobato, and I. Egido, "New challenges to wind energy voltage control. Survey of recent practice and literature review," IET Renew. Power Gener, vol. 12, no. 3, pp. 267-278, Feb. 2018.

[10] Y. Li, Z. Xu, J. Zhang, and K. Meng, "Variable droop voltage control for wind farm," IEEE Trans. Sustain. Energy., vol. 9, no. 1, pp. 491-493, Jul. 2018.

[11] Y. Guo, H. Gao, Q. Wu, H. Zhao, and J, Østergaard, "Coordinated voltage control scheme for VSC-HVDC connected wind power plants," IET Renew. Power Gener, vol. 12, no. 2, pp. 198-206, 2017.

[12] Y. Guo, H. Gao, Q. Wu, H. Zhao, and J, Østergaard, "Enhanced Voltage Control of VSC-HVDC Connected Offshore Wind Farms Based on Model Predictive Control, "IEEE Trans. Sustain. Energy, vol. 9, no. 1, pp. 474487, Jan. 2018.

[13] W. Yan, W. Cui, W. Lee, J. Yu, and X. Zhao, "Pilot-bus-centered automatic voltage control with high penetration level of wind generation, "IEEE Trans. Ind. Appli., vol. 52, no. 3, pp. 1962-1969, Dec. 2016.

[14] B. Zhang, W. Hu, P. Hou, and Z. Chen, "Reactive power dispatch for loss minimization of a doubly fed induction generator based wind farm, "in Proc. IEEE 17th Int. Conf. Elect. Mach. Syst., 2014, pp. 1373-1378.

[15] B. Zhang, P. Hou, W. Hu, M. Soltani, C. Chen, and Z. Chen, "A reactive power dispatch strategy with loss minimization for a DFIG-based wind farm, "IEEE Trans. Sustain. Energy., vol. 7, no. 3, pp. 914-923, Jul. 2016.

[16] L. Yuan, K. Meng, and Z. Dong, "Hierarchical control scheme for coordinated reactive power regulation in clustered wind farms," IET Renew. Power Gener. vol. 12, no. 10, pp.1119-1126, 2018.

[17] Y. Guo, H. Gao, H. Xing, Q. Wu, and Z. Lin, "Decentralized Coordinated Voltage Control for VSC-HVDC Connected Wind Farms Based on ADMM," IEEE Trans. Sustain. Energy, vol. 10, no. 2, pp. 800-810, Apr. 2018.

[18] S. Huang, Q. Wu, Y. Guo, X. Chen, B. Zhou, and C. Li, "Distributed Voltage Control based ADMM for Large-Scale Wind Farm Cluster connected to VSC-HVDC," IEEE Trans. Sustain. Energy, in press, 2019.

[19] S.Tosserams, L. F. P. Etman, P. Y. Papalambros, and J. E. Rooda, "An augmented Lagrangian relaxation for analytical target cascading using the alternating direction method of multipliers," Structural and multidisciplinary optimization, vol. 31, no. 3, pp. 176-189, 2006.

[20] J. Zhao, H. Wang, Y. Liu, Q. Wu, Z. Wang and Y. Liu, "Coordinated restoration of transmission and distribution system using decentralized scheme," IEEE Trans. Power Syst., vol. 34, no. 5, pp. 3428-3442, Setp. 2019.

[21] A. Kargarian and Y. Fu, "System of systems based security-constrained unit commitment incorporating active distribution grids," IEEE Trans. Power Syst., vol. 29, no. 5, pp. 2489-2498, Sep. 2014.

[22] A. Kargarian, Y. Fu, and Z. Li, "Distributed security-constrained unit commitment for large-scale power systems," IEEE Trans. Power Syst., vol. 30, no.4, pp. 1925-1936, Jul. 2015.

[23] J. Martínez, P. C. Kjær, P. Rodriguez, and R. Teodorescu, "Comparison of two voltage control strategies for a wind power plant," in Proc. IEEE/PES Power Syst. Conf. Expo. (PSCE), 2011, pp. 1-9.

[24] K. Christakou, J. LeBoudec, M. Paolone, and D. C. Tomozei, "Efficient computation of sensitivity coefficients of node voltages and line currents in unbalanced radial electrical distribution networks," IEEE Trans. Smart Grid, vol. 4, no. 2, pp. 741-750, 2013.

[25] A. Maknouninejad and Z. Qu, "Realizing unified microgrid voltageprofile and loss minimization: A cooperative distributed optimization andcontrol approach," IEEE Trans. Smart Grid, vol. 5, no. 4, pp. 16211630, Jul. 2014.

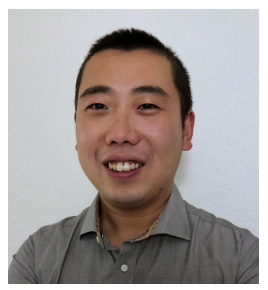

Sheng Huang received the M.S. and Ph.D. degree both in College of Electrical and Information Engineering, Hunan University, Changsha, China, in 2012 and 2016, respectively. He is currently a Postdoc with the Center for Electric Power and Energy, Technical University of Denmark. His research interests include renewable energy generation, modeling and integration study of wind power, control of energy storage system, and voltage control. 


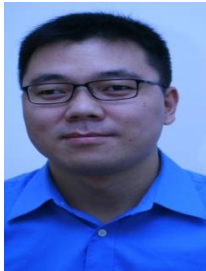

Qiuwei Wu(M'08-SM'15) obtained the PhD degree in Power System Engineering from Nanyang Technological University, Singapore, in 2009.

He was a senior R\&D engineer with VESTAS Technology R\&D Singapore Pte Ltd from Mar. 2008 to Oct. 2009. He has been working at Department of Electrical Engineering, Technical University of Denmark (DTU) since Nov. 2009 (PostDoc Nov. 2009-Oct. 2010, Assistant Professor Nov. 2010-Aug. 2013, Associate Professor since Sept. 2013). He was a visiting scholar at Department of Industrial Engineering \& Operations Research (IEOR), University of California, Berkeley, from Feb. 2012 to May 2012 funded by the Danish Agency for Science, Technology and Innovation (DASTI), Denmark. He was a visiting professor named by Y. Xue, an Academician of Chinese Academy of Engineering, at Shandong University, China, from Nov. 2015 to Oct. 2017. He was a visiting scholar at the Harvard China Project, School of Engineering and Applied Sciences, Harvard University from Nov. 2017 Oct. 2018 funded by the Otto Mnsted Fond.

His research interests are operation and control of power systems with high penetration of renewables, including wind power modelling and control, active distribution networks, and operation of integrated energy systems. He is an Editor of IEEE Transactions on Smart Grid and IEEE Power Engineering Letters. He is also an Associate Editor of International Journal of Electrical Power and Energy Systems, and Journal of Modern Power Systems and Clean Energy. He is a subject editor for IET Generation, Transmission \& Distribution, and IET Renewable Power Generation.

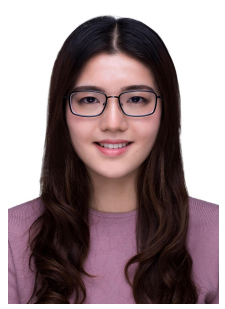

Jin Zhao(S' 17) received the B.Sc. degree in electrical engineering in 2015 from Shandong University, Jinan, China, where she is working toward the Ph.D. degree in electrical engineering.

She is currently a visiting Ph.D. student at the Department of Electrical Engineering, Technical University of Denmark (DTU). Her research interests include power system resilience, transmission and distribution system restoration, renewable energy integration, and power system optimization.

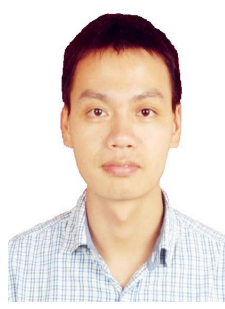

Wu Liao received the B.Sc. degree in automation in 2010 from Hunan University, Changsha, China, and the $\mathrm{Ph} . \mathrm{D}$. degree in electrical engineering from Hunan University, Changsha, in 2016. He was with CRRC Zhuzhou Institute Co., Ltd., Zhuzhou, China, as a converter software designer and researcher between 2016 and 2019 . He is currently with Hunan University as a Postdoctoral Researcher at the Department of Electrical Engineering. His research interests include wind power generation, modular multilevel converters, high power motor drives. 